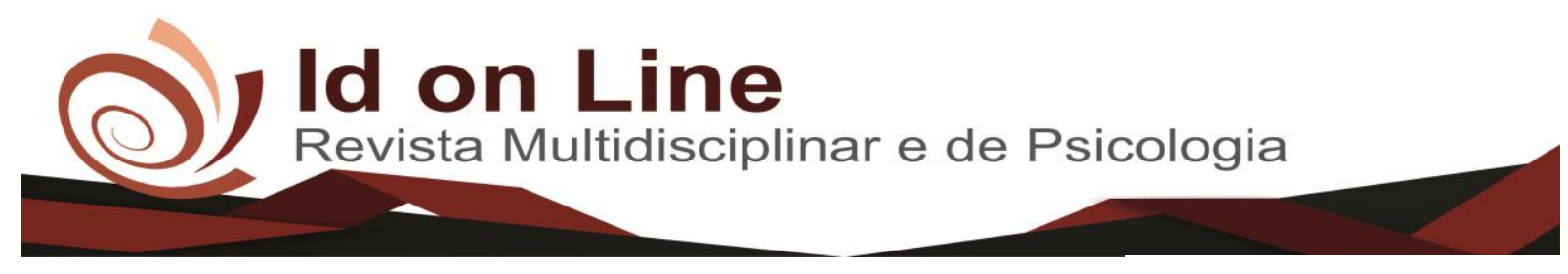

Artigo

\title{
Gramaticalização do item Linguístico Mesmo: Funções Polissêmicas do Uso
}

\author{
Maria Leuziedna Dantas ${ }^{1}$; Sayonara Abrantes de Oliveira Uchôa ${ }^{2}$; \\ Symara Abrantes Albuquerque de Oliveira Cabral ${ }^{3}$; Ginete Cavalcante Nunes ${ }^{4}$
}

\begin{abstract}
Resumo: A proposta deste trabalho é analisar as funções polissêmicas ativadas pelos valores focalizadores apresentados pelo item linguístico mesmo, a partir dos meandros discursivo-pragmáticos motivados pelos contextos de uso da Língua, nos processos de interação entre os falantes. Os dados considerados para a análise sincrônica provêm de entrevistas que integram o Corpus Discurso \& Gramática: a língua falada e escrita na cidade de Natal-RN. Para tanto nos respaldamos em Martelotta e Frederico (2009), Hopper e Traugott (2003), Heine e Kuteva (2007) que tratam do papel dos valores focalizadores apresentados por esse item, assim como a trajetória de gramaticalização. Os dados apontam que o valor concessivo de aspecto conjuncional atesta a hipótese de que o item mesmo reflete uma trajetória de gramaticalização, já que a inter(subjetividade) nos usos motiva a relação de decategorização desse item.
\end{abstract}

Palavras-chave: Polissemia. Funcionalismo. Gramaticalização.

\section{Grammaticalization of the Linguistic Item "Same": The Polysemic Functions of its Use}

\begin{abstract}
The purpose of this work is to analyze the polysemic functions activated by the focus values presented by the linguistic item itself, based on the discursive-pragmatic meanders motivated by the contexts of language use, in the interaction processes among the speakers. The data considered for the synchronic analysis come from interviews that integrate the Corpus Discourse \& Grammar: the language spoken and written in the city of NatalRN. For this, we support Martelotta and Frederico (2009), Hopper and Traugott (2003), Heine and Kuteva (2007) that deal with the role of the focus values presented by the item, as well as the grammaticalization trajectory. The data indicate that the concessive value of conjunctural aspect attests to the hypothesis that the item itself reflects a trajectory of grammaticalization, since the inter (subjectivity) in the uses motivates the decategorization relation of

this

item.
\end{abstract}

Keywords: Polysemy, Functionalism, Grammaticalization.

\footnotetext{
${ }^{1}$ Mestrado em Educação pela Universidade Federal da Paraíba (2010) e especialização em Linguística Aplicada pela Universidade Estadual do Rio Grande do Norte (2003). Atualmente é professora do ensino básico técnico e tecnológico do Instituto Federal de Educação, Ciência e Tecnologia da Paraíba -IFPB;

${ }^{2}$ Doutoranda e Mestre em Linguística pela UFPBLPROLING, pesquisadora nas áreas de Semântica e Linguística Aplicada. Possui graduação em LICENCIATURA PLENA EM LETRAS pela Universidade Federal de Campina Grande (2003). Atualmente é professora efetiva do Instituto Federal de Educação, Ciência e Tecnologia da Paraíba- Campus Cajazeiras - PB Sayonara Abrantes de Oliveira Uchôa. Contato: sayonara_abrantes@ hotmail.com / sayonara.uchoa@ifpb.edu.br;

${ }^{3}$ Graduação em Enfermagem pela Universidade Federal de Campina Grande (2011). Especializações em: Saúde da Família, Obstetrícia, Gestão e Metodologias ativas. Mestrado multiprofissional em Sistemas Agroindustriais com ênfase na saúde. Cursando Doutorado em Ciências da Saúde pela Santa Casa da Misericórdia de São Paulo. Contato: symaraabrantes_@hotmail.com;

${ }^{4}$ Mestre em Letras no âmbito do Programa PROFLETRAS na Universidade Federal Rural de Pernambuco- UFRPE, Unidade Acadêmica de Garanhuns UAG, conclusão em 2016. Especialização em Políticas Educativas e Docência do Ensino Superior pela Faculdade de Formação de Professores de Araripina (FAFOPA) em 2014. Cursa atualmente Bacharelado em Direito pela Faculdade de Ciências Humanas e Sociais de Araripina (FACISA). Graduada em Letras - Inglês pela Faculdade de Formação de Professores de Araripina (FAFOPA) em 2010. Contato: ginetecavalcante@ gmail.com.
} 


\section{Introdução}

O objetivo deste trabalho é analisar os usos polissêmicos ativados pelos valores focalizadores apresentados pelo item linguístico mesmo, motivados pelos contextos de uso da Língua, nos processos de interação entre os falantes. Faz-se oportuno verificar os comportamentos funcionalistas desse item, tendo em vista a teoria da gramaticalização (HOPPER; TRAUGOTT, 2003), tão discrepante da abordagem da Gramática Tradicional que impõe uma restrição ao uso, limitando-se a caracterizá-lo em três categorias: pronome demonstrativo, advérbio ou conjunção.

Os dados selecionados para a análise fazem parte do Corpus Discurso \& Gramática: a língua falada e escrita na cidade do Natal-RN, organizado por Furtado (1998). Os informantes são adultos do Ensino superior e jovens entre 15 e 17 anos, estudantes do ensino médio que produziram distintos tipos de textos tais como: narrativa de experiência pessoal, narrativa recontada, descrição de local, relato de procedimento e relato de opinião. É importante destacar que Martelotta e Frederico (2009) fizeram uma análise do item mesmo, com base no Corpus Discurso \& Gramática- secção Rio de Janeiro. Diante disso, este trabalho investiga as ocorrências do uso do item mesmo em outra região, no caso nordeste, tendo em vista a possibilidade de também observar a existência dessa polissemia dos usos, em falantes de Natal do estado Rio Grande do Norte.

Para tanto nos respaldamos em Martelotta e Soares (2009), Hopper e Traugott (2003), Lopes (2010) entre outros, que tratam dos estudos de processo de gramaticalização numa abordagem funcionalista, tendo em vista as mudanças da língua graças à dinâmica que se opera do léxico à gramática. Destacamos a ideia colocada por Hernandes (2014) no tocante à metáfora da dinâmica do rio, o qual sofre mudanças em sua forma através dos efeitos causados pelas ações do homem e entropia natural.

Neste sentido, a língua também passa por mudanças ocasionadas pelo uso contínuo nos contextos comunicativos do homem, pois "A tradição sobre gramaticalização permite interpretar que só terá se gramaticalizado o item que tenha sofrido de(s) categorização". (HERNANDES, 2014, p.5). Com isso, podemos entender que a decategorização atesta a gramaticalização, fazendo com que itens da língua já não mais pertençam as suas categoriasfontes. 
Com base nestes pressupostos, apresentamos a hipótese de que o item linguístico mesmo permite uma polissemia de usos, realizando trajetória de gramaticalização em virtude das estratégias argumentativas usadas pelo falante para interagir, fazendo com que esse item assuma funções discursivo-pragmáticas polissêmicas.

\section{Gramática Tradicional e Gramática Funcional: Pontos de vista divergentes}

Segundo a Gramática tradicional a base para definir o funcionamento consiste em apresentar um conjunto de normas que regulam o uso da norma culta. Neste sentido, Antunes (2014, p.30) afirma que "a gramática é particularizada, ou seja, não abarca toda a realidade da língua, pois contempla apenas aqueles usos considerados aceitáveis na ótica da língua prestigiada socialmente". Esse caráter predominantemente normativo limita as possíveis utilizações dos usos linguísticos, definindo o certo e o errado, regulando as normas tidas como de prestígio em oposição às aquelas que fogem ao padrão ditado pelas convenções da Gramática Tradicional (doravante GT).

Partindo desta concepção normativa o item linguístico mesmo é alvo de engessamento classificatório, na medida em que normalmente é caracterizado como pronome demonstrativo, como advérbio ou como conjunção (BECHARA, 2009; ROCHA LIMA, 1997). Além disso, o item é alvo de discursos que regulam o uso, através de várias situações de certo e errado, conduzindo à higienização gramatical nos compêndios da Gramática Tradicional. Cipro Neto (2011), ao analisar o uso do item mesmo, diz que o uso frequente como equivalente ao pronome ele, parece um tanto deselegante. Assim, observarmos que a concepção de língua para GT é um conjunto de regras conforme afirma Bechara (2009, p.26) "A norma contém tudo o que na língua não é funcional, mas que é tradicional, comum e constante, ou, em outras palavras, tudo o que se diz assim, e não de outra maneira".

Embora Bechara (2009, p.156-157) afirmando na secção “Outros demonstrativos e seus empregos" que o item mesmo pode denotar identidades e com o valor de "em pessoa" é classificado como demonstrativo, além de apresentar valores demonstrativos anafóricos, destacamos que a polissemia dos usos não é contemplada tendo em vista a relação de integração linguística nos contextos comunicativos de seus usuários, ampliando a funcionalidade e produtividade desse item. 
Podemos observar que do ponto de vista da Gramática Funcional há uma posição divergente uma vez que o item mesmo apresenta diversos valores, numa relação polissêmica relacionada às estratégias de argumentação. Com base em Martelotta e Frederico (2009) a noção de focalização ativa o alto nível de pressuposicionalidade e previsibilidade das informações veiculadas pelo falante com o objetivo de atingir o propósito comunicativo.

Desta forma, a Gramática Funcional tenta compreender a funcionalidade da língua, para além de classificações estruturais, descrevendo o seu funcionamento real, ao reconhecer a instabilidade entre estrutura e função, devido à dinamicidade das situações comunicativas típicas da interação entre falantes. De acordo com Neves (1997, p.2) "Qualquer abordagem funcionalista tem como questão básica de interesse a verificação de como se obtém a comunicação com essa língua”. A autora critica a devoção às regras da GT, isenta de reflexão que fortalecem os preconceitos linguísticos, desse modo reconhece os impasses de um ensino voltado para "gramatiquices" em vez da aplicabilidade da língua, perante a heterogeneidade e flexibilidade de usos.

Para perspectiva funcional é importante a noção de gramática emergente, pois sempre estão surgindo novas funções, valores e usos para as formas existentes. E diante dessa questão, verificamos a ocorrência da mudança da língua decorrente da gramaticalização. Hopper e Traugott (2003) define a gramaticalização como um processo pelo qual itens e construções gramaticais passam, em determinados contextos linguísticos, a servir a funções gramaticais, e uma vez gramaticalizados, continuam a desenvolver novas funções gramaticais.

Observamos a abordagem da gramaticalização e as regularidades da mudança, pautadas na noção de unidirecionalidade que vê mudanças de elementos lexicais para elementos gramaticais em determinados contextos de uso da língua, conforme afirma Martellota (2011, p.74): “Tomemos alguns exemplos de mudança por gramaticalização, que provê o surgimento de elementos de valor gramatical como conjunções, verbos auxiliares e outras categorias de elementos que ajudam a organizar o texto nas diferentes situações de comunicação".

Pode-se dizer que a gramaticalização é tratada como um fenômeno a partir do movimento em que certos elementos que atuam no nível representacional (referência ao universo biossocial) passam a atuar no nível interpessoal (elementos processuais definidos como gramaticais).

Assim, a gramaticalização é postulada por Martelotta (2011, p. 92): 
Como um processo de mudança linguística unidirecional, segundo o qual itens lexicais e construções sintáticas, em determinados contextos, passam a assumir funções gramaticais e, uma vez gramaticalizados, continuam a desenvolver novas funções gramaticais. Seguindo esse processo, o elemento deixa de atuar no nível representacional, característico dos elementos que fazem referência a dados mais objetivos associados ao nosso mundo biossocial, para atuar no nível interpessoal, que engloba as expressões de valor processual, ou seja, aquelas cujas funções estão relacionadas aos processos através dos quais o falante elabora seu enunciado para um determinado ouvinte em um contexto específico de uso.

Como suporte para ilustrar essa teoria, esse autor cita vários exemplos de gramaticalizações tais como: passagem de vocábulo para afixo, passagem de verbo pleno para auxiliar, passagem de advérbio para conjunção, passagem de advérbios de modo para modalizador e passagem de advérbios de modo para marcador discursivo. Esses exemplos ilustram coerentemente a capacidade do fenômeno se dá numa dimensão unidirecional, ou seja, os elementos do nível representacional passam a ser mais gramaticais.

Sobre isso, Lopes colabora afirmando (2010, p.277):

É como se os elementos lexicais fossem perdendo suas potencialidades referenciais de representar ações, qualidades e seres do mundo biossocial e fossem ganhando a função de estruturar o léxico na gramática , assumindo por exemplo posições mais fixas sentença e expressando noções gramaticais como tempo, modo, aspecto, etc.

Diante da tarefa de evidenciar os usos reais da língua, a fim de verificar como os elementos perdem as potencialidades referenciais, destacamos os parâmetros de gramaticalização propostos por Heine e Kuteva (2007) e motivações para tal processo.

1. A extensão caracteriza-se pelo sentido estendido de certas expressões, construindo novos valores da expressão dependendo do contexto de uso.

2. Dessemantização conceituada pela perda de conteúdo semântico

3. Decategorização que é uma mudança de classe gramatical.

4. Erosão - caracteriza-se pela perda de substância fonética por coalescência ou condensação.

Esses são, então, os quatro parâmetros determinantes para a gramaticalização. E para a manifestação da própria mudança da língua vários fatores são apontados como motivadores (MARTELOTTA, 2011): a) A necessidade de expressar domínios abstratos da cognição em termos de domínios concretos. b) A negociação do sentido por falante e ouvinte no ato da 
comunicação. c) A tendência dos ouvintes para selecionar estruturas ótimas. d) A tendência dos falantes para usar expressões novas e extravagantes. e) Iconicidade, marcação e frequência.

Essas motivações são importantes para determinar a gramaticalização que se opera do léxico à gramática, do concreto ao abstrato. E para tal mudança, é pertinente a compreensão de que a língua não é arbitrária, pois há uma relação entre forma e função, influenciada por fatores cognitivos e comunicativos.

A negociação do sentido por falante e ouvinte no ato da comunicação, oportuniza uma produtividade significativa do item mesmo, motivando a mudança semântica direcionada à subjetivação, com ênfase no falante e à intersubjetivação, ênfase na recepção de como o ouvinte recebe a mensagem. Como base, nestes princípios, apresentamos a seguir a polissemia dos usos com ênfase na focalização.

\section{Polissemia dos usos do item Mesmo}

O item mesmo desempenha funções polissêmicas ativadas pelos valores focalizadores, tendo em vista os processos de interação entre os falantes. Tendo como respaldo o trabalho de Martelotta e Frederico (2009) a noção de foco implica em uma restrição ao campo de visão, limitando o sentido dos elementos, enfatizando, intensificando ou excluindo uma determinada informação.

Essa noção de focalização permite entender que o item mesmo se apresenta como um elemento semântico-pragmático atribuído à determinada expressão para destacar o grau de importância dessa expressão, como informação nova ou contrastante, tendo em vista a preocupação do falante em deixar clara a informação, na tentativa de anulação de outras interpretações por parte do ouvinte.

Com base nos dados sincrônicos, partimos da premissa de que o item linguístico mesmo realiza trajetória de gramaticalização baseados em três parâmetros de Heine e Kuteva (2007), no sentido de que os aspectos discursivo-pragmáticos levam à produção extensiva em direção à (inter) subjetividade, demarcando a força elocutória do falante. Com isso, há também dessemantizações, referente à alteração no significado, bem como a descategorização, no tocante à perda de propriedades morfossintáticas da forma fonte lexical ou menos gramatical. 
Para entender o funcionamento polissêmico do item mesmo, passamos a analisá-lo em duas vertentes como valores adnominais e valores adverbiais. Os usos adnominais representam a focalização no grau representacional, refletindo a verificação de identidade e congruência.

\section{Valores adnominais}

Em relação aos valores adnominais, o uso do mesmo modifica o substantivo e pronomes pessoais para enfatizar uma relação de identidade e congruência. Ou seja, o falante focaliza o item na tentativa de mostrar certa igualdade e semelhança entre referentes informacionais. Para tanto, são apresentados vários usos, entre eles o uso como valor anafórico nominal, conforme exemplo (1):

(1) é ... eu vou descrever a ... a UNIPEC né ... onde eu passo ... eu passo o dia todo em casa e eи ... o melhor lugar que eu acho pra ... o melhor lugar que eu passo durante o dia ... quando eu saio é na ... na ... lá na ... na faculdade mesmo ... onde eu tenho meus amigos lá e tudo...

Esse trecho faz parte de narrativa oral, da tipologia descrição de local, a informante descreve a faculdade UNIPEC, fazendo uso o item mesmo de modo focalizador como anafórico nominal, com o objetivo de modificar enfaticamente o referente anteriormente expresso UNIPEC. Entendemos a anáfora, de acordo com as palavras de Santos, (2004, p. 197) "como processo de remissão a conteúdos já expressos no texto/discurso Isso revela uma relação entre elementos constitutivos da frase". Essa relação de identidade com o referente é construída tendo em vista a maneira como o falante pretende ser claro ao ouvinte, na tentativa de não deixar dúvidas quando ao sentido almejado.

Além disso, consideramos a sentença (2):

(2) I: é ... o óleo num absorve muito a poeira ... mas eu acredito também que os seus donos zelem um pouco né? porque de vez em quando eu dou uma pin/ uma limpada nesses quadros assim ... eu noto um pontinho de mosca no quadro ... então eu vou lá com cotonete e com água e dou uma limpada ... E: água ... água mesmo ... I: é ... com cotonete e água e dou uma limpada ... E: isso não prejudica ... 
Observamos que em (2) não houve a concordância com o substantivo feminino água, assim como em (1). O item apresenta um caráter anafórico determinando um elemento mencionado, com valor de identidade, mas não aparece com flexão.

Outro uso com esse caráter anafórico, também é possível verificar o item mesmo com alto valor de pressuposicionalidade, fazendo menção de forma indireta, a informações mencionadas.

(3) E2: e no caso dos assassinos que já foram presos ... e voltam a cometer cinco ... dez ... quinze vezes ... o mesmo ... a mesma ... o mesmo crime ... e não adianta nada?

No relato de opinião sobre o tema pena de morte, a entrevistadora faz esse questionamento ao informante, utilizando o item mesmo com alto grau de pressuposicionalidade, pois ativa uma informação linguística implícita de que, anteriormente, havia-se cometido o crime. Para Ducrot (1987, p.33) o pressuposto linguístico "pertence antes de tudo à frase: ele é transmitido da frase ao enunciado na medida em que deixa entender que estão satisfeitas as condições de emprego da frase da qual ele é a realização". Nas interações, os pressupostos marcam a força enunciativa, fazendo com que o interlocutor, através do conhecimento partilhado, influencie o outro.

O uso com valor inferível pode aparecer modificando não apenas um item nominal, mas também uma cláusula inteira, refletindo um contexto de pressuposicionalidade, como se verifica no exemplo (4):

(4) cada um dando uma força de um conselho ... pra que viesse melhor ... era um amor verdadeiro ... depois disso a gente continuava o mesmo ritmo né ... tomava café ... descia pra praia ... brincava ... jogava ... voltava novamente ... à tarde ...

O mesmo reflete um contexto de pressuposição quando percebemos que já havia um ritmo mantido anteriormente. Neste exemplo, esse o item está em referência à gradação de ações rotineiras marcantes no relato de experiência vivido pela informante, durante a realização de um retiro de carnaval da praia de Coqueiros.

Além de valores anafóricos, o item mesmo possibilita o uso como valor dêitico normalmente modificando um pronome pessoal, (concordando ou não com ele) ou outro advérbio, neste caso é invariável. 
(5).. né ... chegou na estrada ... então perguntando se ele era Martin ... aí ele disse ... "é ... sou eu mesmo" ... ele disse ... "pronto ... eu tenho uma correspondência para lhe entregar ... agora eu tenho essa..

No caso (5), o informante faz referência concordando com o masculino singular. Por outro lado não foram localizados no corpus de Natal, o uso de mesmo concordando com o pronome feminino ela. Por outro lado, localizamos o uso em referência ao pronome demonstrativo, em que a informante faz referência à aquela, mas faz a flexão de pessoa.

(6) o que eu tenho ... o que tenho analisado ... o que tenho visto quando você começa a conhecer de perto ... cada sertanejo ... cada pessoa nordestina ... aquela mesmo que sente a situação ... que passa ... que passa o seu país e a vida que ela atravessa a cada dia ...

Com valor dêitico espacial e temporal, não há casos de concordância, conforme trechos (7 e 8):

(7)... I: e aqui mesmo na ... na zona urbana ... nesse perímetro urbano ... eu consigo ... eu consigo esse ... esse afastamento ... E: mas em termos assim é ... de aspectos de algum ponto que você ... que te chame atenção ... da mesma forma como a vegetação ...

(8) aí a convivência é maior ... mas com esse outro ... pra você ver ... um dia desse eu tava me lembrando ... ontem mesmo ... eu tinha vergonha de comer na frente de Alexandre ... às vezes a gente ia lanchar ... e eu ficava entalada ... era ... e com ele não ... o Tarcísio ...

Desta forma, entendemos que o item mesmo apresenta uma ambiguidade entre valor adnominal e valor adverbial. Como valor adnominal, aparece modificando um pronome (nomes) e como valor adverbial, verificamos uma relação duvidosa, que não permite justificálo como invariável. Nesse sentido, Martellota e Frederico (2009, p. 17) afirmam:

Não podemos dizer se mesmo modifica os dêiticos, permanecendo na forma tipicamente invariável do masculino singular porque o advérbio modificado não se flexiona, ou se ele é invariável porque assume de fato função de advérbio. Em outras palavras temos aqui um típico contexto gerador de novos usos, em que a ambiguidade leva à reanálise do elemento. 


\section{Usos adverbiais}

A invariabilidade é o que caracteriza o uso de acordo com o uso adverbial. De acordo com Martelotta e Frederico (2009, p.19) quatro diferentes tipos são recorrentes: o focalizador propriamente dito com valor restritivo, que resulta basicamente de verificação de coincidência com o protótipo; o enfatizador de factualidade e o marcador de premissa, que refletem verfificação de factualidade; e o inclusivo, relacionado à verificação de confronto de topologias.

Valor restritivo: se caracteriza focalizando sua prototipicidade, demarcando uma escala de argumento mais importantes em detrimentos a outros.

(9) .. fez algum crime ... sabe que a pena de morte taí ... vai ser julgado com pena de morte ... então pense antes de fazer ... porque depois que tiver feito ... minha filha ... é morte na certa ... e por isso mesmo que eu acho que ia dar certo ... sabe? porque as pessoas iam pensar mais ... num era só matar ... “não ...

No exemplo (9), o falante expressa sua opinião favorável à pena de morte, e para tanto faz uso do item mesmo para focalizar um argumento mais importante em relação à defesa da implantação desse regime em nosso país, como solução para resolver os problemas da criminalidade social.

Valor de premissa: O falante toma como verdade a hipótese, pressupondo que inevitavelmente vai acontecer. No exemplo (10), verificamos que o falante focaliza o item para revelar argumentos lógicos que levam a uma conclusão de que os políticos do Brasil não vão investir em Educação.

(10) então você passa o segundo grau todinho estudando ... aprendendo ... né ... só assim pode entrar na universidade ... então acho que aí vem a questão de política no Brasil ... porque o pessoal num investe na educação ... né ... é brasileiro é ... principalmente político né ... começa pelos grandes ... querem mais que ... a gente que tem estudo ... que conhece ... sabe o que quer ... eles querem que a gente ... num tenha capacidade de discernir o que é certo e o que é errado ... então ... por isso mesmo eles não vão investir numa classe ...

Com valor inclusivo: é marcado pela informação em estado mínimo de uma escala de expectativa, ou seja, o falante informa algo excepcional aos padrões tidos normais. De acordo com a situação descrita no exemplo (11), entendemos que "passar chifre", dentro da variante nordestina é trair alguém, apresentando como ato extremo em uma relação conjugal, numa sociedade com regime de monogamia. 
(11) quando eu cheguei lá ... eu já ia com o intuito de ir mesmo pra ... passar um chifre ... aí ... quando cheguei lá ... fui pra uma festa ... inclusive ... era dia primeiro ... aí no dia dois era meu aniversário ... aí eu fui pra lá ... cheguei lá ... fui pra festa ... aí arranjei um namorado ... e isso minha filha ... pra você ver ... e disse pro rapaz. ... que eu tinha um namorado ... que gostava muito dele ... sabe?

Com valor concessivo: A ideia de concessão está diretamente ligada ao contraste, à quebra de expectativa diante das informações. O item mesmo estabelece uma oposição entre informações, admitindo uma possibilidade de refletir uma tendência de mudança por gramaticalização de advérbio > conjunção e assim desliza-se da sua categoria prototípica, dessemantizando-se em função do contexto de uso dos falantes. No exemplo (12), quebra-se a expectativa de não tomar vinho, embora seja um jantar, seja uma noite.

(12) mas lá em casa ninguém é muito chegado a vinho ... então eu prefiro fazer uma senhora limonada ... porque não gosta de vinho ( ）... porque lá em casa ... a gente mora aqui nesse clima ... então não é muito convidativo você ficar tomando vinho ... mesmo à noite ... mesmo que seja um jantar ... pra você comer com esse peixe ... aqui em casa ... na minha casa ... no caso ... a gente não tem assim ... esse costume de tomar vinho

Assim, neste exemplo verificamos a força adaptativo-funcional do item mesmo diante das necessidades comunicativas do usuário, desestabilizando a prototicipicidade de advérbio, para atuar como conjunção, mostrando que atividade do discurso redimensiona as categorias gramaticais.

\section{Conclusão}

Com base nas análises dos dados estudados, compreendemos que o item Mesmo apresenta uma polissemia de usos que se manifesta em dois grupos: adnominais e adverbiais, relacionados às pressões argumentativas do falante na tentativa de veicular as estratégias que giram em torno do grau de informatividade representacional e de pressuposicionalidade das sentenças. 
Essa polissemia associada aos aspectos discursivos-pragmáticos permite a fluidez das categorias, deslizando para uma invariabilidade quando se relacionam aos usos dêiticos em oposição à variabilidade dos usos adnominais.

Destacamos que o valor concessivo de aspecto conjuncional atesta a hipótese de o item reflete uma trajetória de gramaticalização já que a inter (subjetividade) motiva a relação de decategorização do item.

Portanto, verificamos que os falantes de Natal-RN, no tocante aos usos discursivopragmáticos do item, refutam a posição defendida por Martelotta e Frederico (2009) de que o vocábulo mesmo apresenta trajetória de gramaticalização decorrente das pressões do uso, tendo em vista a argumentação e necessidade de interação.

\section{Referências}

ANTUNES, Irandé. Muito além da gramática: por um ensino de línguas sem pedras no caminho. São Paulo: Parábola Editorial, 2007.

BECHARA, Evanildo. Moderna gramática portuguesa. 37. ed. Rio de Janeiro : Nova Fronteira, 2009.

CIPRO NETO, Pasquale. Eu tenho medo do mesmo. Disponível em: http://www1.folha.uol.com.br/fsp/cotidian/ff0505201104.htm. Acesso em : 10 de agosto de 2016.

DUCROT, Oswald. O dizer e o dito. Campinas-SP: Pontes, 1987.

FURTADO DA CUNHA, M. A. (Org.). Corpus Discurso \& Gramática: a língua falada e escrita na cidade do Natal. Natal: EDUFRN, 1998.

HEINE, Bernd; KUTEVA, Tania. The genesis of gramar: a reconstruction, New York: Oxfor University Press.

HERNANDES, Maria Célia Lima. Decisões metodológicas durante a descrição da língua na abordagem funcionalista. Revista Prolíngua. Dossiê Funcionalista. Apresentação: SILVA, Camilo Rosa, FREITAG, Raquel Meister Ko. ISSN 1983-9979 Vol. 9 - Número 2 - jul/dez de 2014. p. 3-10.

HOPPER, Paul J; TRAUGOTT, Elizabethe-Closs. Grammaticalization. Cambridge: Cambridge Iniversity Press, 2003. 
LOPES. Célia Regina dos Santos. A persistência e a decategorização nos processos de gramaticalização. In: VITRAL, Lorenzo; COELHO, Sueli (Orgs). Estudos de processos de gramaticalização em português: metodologias e aplicações. Campinas- SP, Mercado das Letras, 2010.p. 275-314.

MARTELOTTA, Mário Eduardo e FREDERICO, Elaine Soares. Usos do vocábulo mesmo no português do Brasil: estratégias de focalização. In: JACOB, Daniel (ed.) Syntaxe, structure informationnelle et organisation du discursours dans les langues romanes, 2009 (no prelo).

Mudança Linguística: uma abordagem centrada no uso. São Paulo: Cortez, 2011.

ROCHA LIMA, Carlos Henrique da. Gramática normativa da Língua Portuguesa. Rio de Janeiro: José Olympio, 1976.

NEVES, Maria Helena de Moura. Gramática de usos do Português. São Paulo: UNESP, 2000. A gramática passada a limpo: conceitos, análise e parâmetros. São Paulo: parábola Editorial, 2012.

A gramática funcional. São Paulo: Martins Fontes, 1997.

SANTOS, Neide Correia. Reflexões Funcionalistas em torno do item linguístico mesmo. In: CHRISTIANO, Maria Elizabeth Affonso; SILVA, Camilo Rosa; HORA, Dermeval da. (orgs.).Funcionalismo e gramaticalização : teoria, análise, ensino. João Pessoa : Ideia, 2004.

\section{Como citar este artigo (Formato ABNT):}

DANTAS, Maria Leuziedna; UCHÔA, Sayonara Abrantes de Oliveira; CABRAL, Symara Abrantes Albuquerque de O.; NUNES, Ginete Cavalcante. Gramaticalização do item Linguístico Mesmo: Funções Polissêmicas do Uso. Id on Line Rev.Mult. Psic., 2018, vol.12, n.41, p.1096-1108. ISSN: 1981-1179.

Recebido: $11 / 07 / 2018$.

Aceito: $26 / 07 / 2018$ 